\title{
Glomus Tumor of the Stomach Simulating a Gastrointestinal Stromal Tumor: A Case Report and Review of Literature
}

\author{
Edouard Matevossian ${ }^{a} \quad$ Björn L.D.M. Brücher ${ }^{c}$ Jörg Nährig ${ }^{b}$ \\ Hubertus Feußner ${ }^{\mathrm{a}}$ Norbert Hüser ${ }^{\mathrm{a}}$ \\ aDepartment of Surgery and ${ }^{b}$ Institute of Pathology, Technical University of \\ Munich, Munich, 'Department of Surgery, Comprehensive Cancer Center, \\ University of Tübingen, Tübingen, Germany
}

\section{Key Words}

Glomus tumor · Gastric glomangioblastoma · GIST

\begin{abstract}
Glomus tumor is an infrequent and in most cases benign mesenchymal neoplasia which affects subcutaneous/submucosal tissue and occurs in the gastrointestinal tract, solid organs (e.g. liver, kidney) and the extremities. Visceral glomus tumor of the stomach generally presents with non-specific epigastric pain, loss of appetite and Gl bleeding (melaena), often without haemodynamic instability. Macroscopic appearances on upper $\mathrm{Gl}$ endoscopy are non-diagnostic. Endosonographic appearances are generally heterogenous and poorly-reflective, hence fail to differentiate glomus tumor from other potential diagnoses. Histological confirmation of the diagnosis is only possible when a fine needle biopsy is inclusive of abnormal tissue. These difficulties in diagnosis mean that in many cases, only immunohistochemical analysis of surgically resected tissue can distinguish glomus tumor from several possible differentials. Therefore, endoscopicallyassisted laparoscopic curative wedge-resection of a lesion suspicious for glomus tumor of the upper gastrointestinal tract must be considered first-line in terms of a combined investigative and curative approach.
\end{abstract}

\section{Introduction}

First-line procedural investigations for non-specific epigastric pain include endoscopy and endosonography, combined with biopsy of suspicious areas in the upper gastrointestinal tract. Despite high sensitivity and specifity, obtaining a definite histopathologic differentiation is sometimes unsuccessful, particularly if biopsy is not 
representative, e.g. because of tumor bleeding into the affected tissue. In such a case, the single remaining diagnostic option is a curative laparoscopic endoscopically-assisted wedge-resection of the stomach. We present an interdisciplinary case report in which a tumor of the stomach, suspicious for GIST, was removed surgically and was found to be a benign glomus tumor by definitive histology.

\section{Case Report}

A 44-year old patient presented with relapsing epigastric pain of variable intensity and tarry stool, beginning three days earlier. There were no clinical or laboratory findings to suggest an acute posthemorrhagic anemia (hemoglobin $14.7 \mathrm{~g} / \mathrm{dl}$, hematocrit $43.2 \%$, PT 118\%, aPTT $27 \mathrm{~s}$ ). Upper endoscopy and endosonography were performed, revealing a spherical, submucosal, solid tumor approximately $50 \mathrm{~mm}$ in diameter located in the pyloric antrum (fig. 1a). Overlying ulceration was considered the likely source of bleeding, and fine needle biopsy of the lesion (19G) was performed, followed by preventive clip-application. An endosonographic picture with a poorly reflective, nonhomogeneous pattern and echo-free areas was compatible with a $35 \times 30 \mathrm{~mm}$ GIST (fig. 1b). Histology was equivocal, revealing only a hemorrhagic biopsy sample without representative cells. Investigations thus far were inadequate to exclude a malignant process, and surgery (endoscopically-assisted laparoscopic wedge-resection of the stomach) was indicated.

Histological section of the surgical specimen revealed a rare benign glomus tumor (positive reaction on markers specific for glomus tumor (vimentin/actin), fig. 2a; no reaction with CD-117 antibodies was seen, fig. 2b). The excised specimen had histologically clear margins (Ro). The patient's symptoms completely settled, leading to discharge five days postoperatively. Endoscopy was performed 6 months later, and demonstrated normal gastric mucosa.

\section{Discussion}

Glomus tumor is a (quite) rare neoplasm and despite local invasion of vessels is mostly benign. It is often found in the skin (particularly in the dermis/subcutaneous tissues of the limbs), but can also be found in the gastrointestinal tract (usually intramurally in the mucosa/submucosa and serosa) as well as other solid organs [1].

The present assumption that the first glomus tumor of the stomach was identified in 1948 and described with another two cases in 1951 is considered questionable by the authors of this paper [2]. Smol'iannikov wrote that the first glomus tumor of the stomach was clearly described in a 64-year old man in 1928 by Talijeva [3]. Furthermore, the first malignant glomus tumor of the stomach was diagnosed in 1939 by Kirschbaum et al. in a 40 -year old man [4]. There are case reports of malignant glomus tumors of the stomach in girls aged 12-14 years, published by Yannopoulos et al. [5]. In addition, there have been a number of reports pertaining to glomus tumors of solid abdominal/retroperitoneal organs and of the colon [6-8]. There is no gender bias in the incidence of glomus tumors but their peak incidence occurs between the fourth and sixth decade of life.

Immunohistochemically, most glomus tumors show a positive expression of vimentin/actin without expressing chromogranin A, neuronspecific enolase (NSE), carcinoembryonic antigen (CEA) or epithelial membrane antigen (EMA). The rarity of glomus tumor, its variable organ involvement, its non-specific symptoms at presentation and the often equivocal results of standard first line investigations all contribute to diagnostic difficulty. Endoscopic and endosonographic images in glomus tumors of the stomach show a solid, submucosal tumor with or without ulceration and do not differentiate it from other important diagnoses, e.g. GIST, neuro-endocrine neoplasia (carcinoid), angiomyoma or lymphoma [9]. Hence, presurgical diagnostic confirmation is often impossible. Only immunohistochemical analysis of representative biopsies (GIST: 


\begin{tabular}{c|l|l|l}
$\begin{array}{r}\text { Case Reports in } \\
\text { Gastroenterology }\end{array}$ & $\begin{array}{l}\text { Case Rep Gastroenterol 2008;2:1-5 } \\
\text { D0I: 10.1159/000112862 }\end{array}$ & Published online: January 10, 2008 & $\begin{array}{l}\text { O 2008 S. Karger AG, Basel } \\
\text { ISSN 1662-0631 } \\
\text { www.karger.com/crg }\end{array}$ \\
\hline
\end{tabular}

positive reaction with CD-117 antibodies and missing expression of glomus tumor typical actin/vimentin) can confirm the diagnosis, and hence aid the clinician in determining appropriate therapy and prognosis [9-11]. Compounding pre-surgical diagnostic difficulties, there have also been reports of malignant transformation of glomus tumor. Therefore, surgery or en bloc endoscopic enucleation is in most cases the remaining diagnostic and therapeutic option [12,13]. A definite immunohistochemical confirmation of the diagnosis is essential, because the prognosis of a potentially malignant lesion is otherwise unpredictable [11].

In the case presented, a patient with recurring epigastric pain and melaena, there was an endoscopic and endosonographic finding of a submucosal tumor of the gastric antrum. Given the non-diagnostic biopsy result and the ongoing risk of gastrointestinal bleeding, endoscopically assisted laparoscopic wedge-resection of the stomach was performed as a combined diagnostic and therapeutic procedure. Histological and immunohistochemical analysis of the resected tissue showed an entirely removed (Ro) glomus tumor. Unlike GIST, if complete removal of a benign glomus tumor (Ro) is verified histologically, there is no indication for further specific therapy $[14,15]$. Sonographic (for solid organs) and endoscopic follow-up for early detection of recurrence or metastasis constitutes the most reasonable postoperative follow-up.

Fig. 1. a Endoscopy of the glomus tumor, showing a spherical, submucosal solid tumor, located in the pyloric antrum with $\mathbf{b}$ endosonographically poorly reflective, inhomogeneous pattern and echo-free areas.
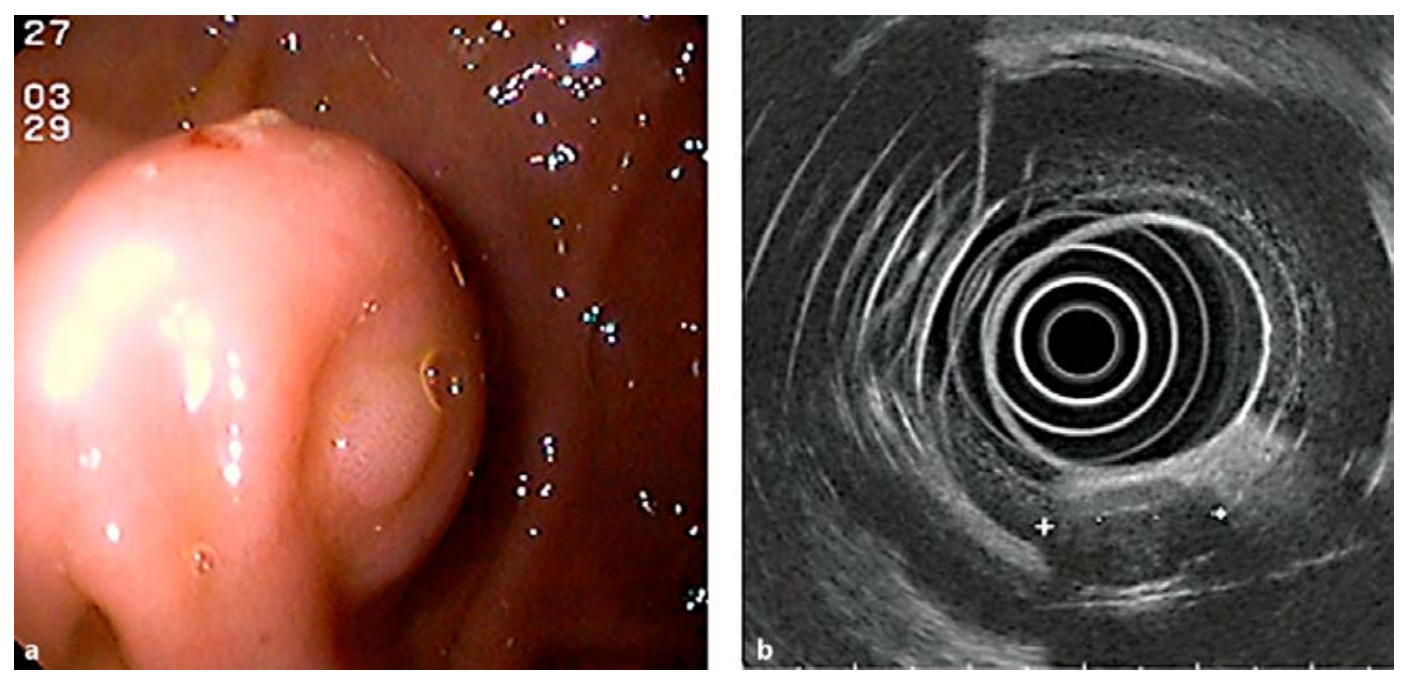


\begin{tabular}{c|l|l|l}
$\begin{array}{r}\text { Case Reports in } \\
\text { Gastroenterology }\end{array}$ & $\begin{array}{l}\text { Case Rep Gastroenterol 2008;2:1-5 } \\
\text { D0I: 10.1159/000112862 }\end{array}$ & Published online: January 10, 2008 & $\begin{array}{l}\text { O 2008 S. Karger AG, Basel } \\
\text { ISSN 1662-0631 } \\
\text { www.karger.com/crg }\end{array}$ \\
\hline
\end{tabular}

Fig. 2. Immunohistochemistry; a negative CD 117-Ab reaction; b positive reaction on vimentin/actin staining (magnification 200×).
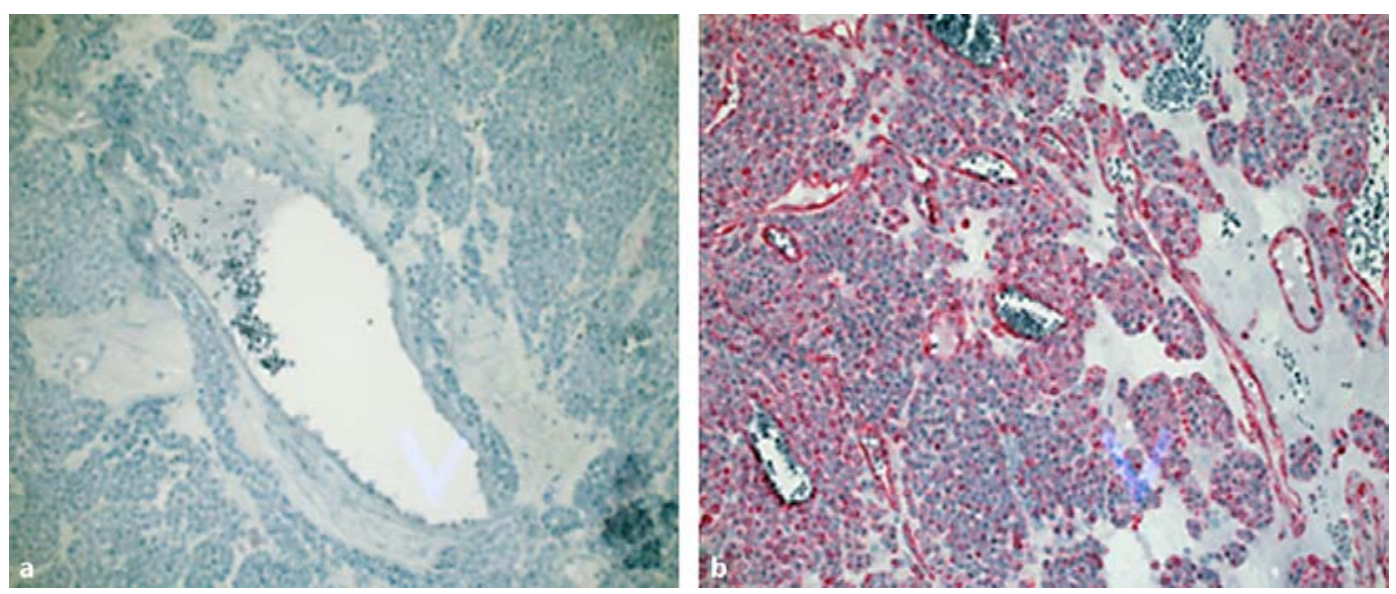


\section{References}

1 Caccamo D, Danedo M, Gordon RE: Glomus tumor of the stomach. Mt Sinai J Med 1987;54:344-347.

2 De Busscher G: Les anatomoses arterioveineuses de l'estomac: An ultrastructural study. Acta Neurol Morphol 1948;6:87-105.

-3 Smol'iannikov A: Glomus tumors. Vopr Onkol 1974;20:104-116.

4 Kirschbaum D, Teitelman L: Malignant tumor of the omentum simulating glomangioma. Arch Path 1939;27:95.

-5 Yannopoulos K, Stout AP: Smoot muscle tumors in children. Cancer 1962;15:958.

6 Oliphant R, Gardiner S, Reid R, McPeake J, Porteous C: Glomus tumour of the ascending colon. J Clin Pathol 2007;60:846.

7 Al-Ahmadie HA, Yilmaz A, Olgac S, Reuter VE: Glomus tumor of the kidney: A report of cases involving renal parenchyma and review of the literature. Am J Surg Pathol 2007;31:585-591.

8 Jaiswal VR, Champine JG, Sharma S, Molberg KH: Primary glomangioma of the liver: A case report and review of the literature. Arch Pathol Lab Med 2004;128:46-49.

9 Gu M, Nguyen PT, Cao S, Lin F: Diagnosis of gastric glomus tumor by endoscopic ultrasound-guided fine needle aspiration biopsy. A case report with cytologic, histologic and immunohistochemical studies. Acta Cytol 2002;46:560566.

10 Debol SM, Stanley MW, Mallery S, Sawinski E, Bardales RH: Glomus tumor of the stomach: Cytologic diagnosis by endoscopic ultrasound-guided fine-needle aspiration. Diagn Cytopathol 2003;28:316-321.

-11 Miettinen M, Paal E, Lasota J, Sobin LH: Gastrointestinal glomus tumors: A clinicopathologic, immunohistochemical, and molecular genetic study of 32 cases. Am J Surg Pathol 2002;26:301-311.

12 Matsumoto K, Kakizaki H, Yagihashi N, Yagihashi S: Malignant glomus tumor in the branchial muscle of a 16-year-old girl. Pathol Int 2001;51:729-734.

13 Park YS, Park SW, Kim TI, Song SY, Choi EH, Chung JB, Kang JK: Endoscopic enucleation of upper-GI submucosal tumors by using an insulated-tip electrosurgical knife. Gastrointest Endosc 2004;59:409-415.

14 Dasaev AN, Stepanov VA: Glomus tumor of the small intestine with metastasis to the liver. Klin Med (Mosk) 1985;63:110-111.

15 Hohenberger P, Wardelmann E: Gastrointestinale Stromatumoren. Chirurg 2006;77:33-40. 